\title{
Comparison of clinical and biological characteristics of HIV-infected patients presenting Cryptococcus neoformans versus $C$. curvatus/C. laurentii meningitis
}

Bive Zono ${ }^{1,7^{*}}$, Michel Moutschen ${ }^{2}$, Hippolyte Situakibanza ${ }^{3}$, Rosalie Sachelii, ${ }^{4,7}$, Gaultier Muendele ${ }^{5}$, Pius Kabututu', Adolphe Biakabuswa ${ }^{6}$, Nicole Landu ${ }^{6}$, Georges Mvumbi ${ }^{1}$ and Marie-Pierre Hayette ${ }^{4,7}$

\begin{abstract}
Background: Cryptococcal meningitis is mainly caused by Cryptococcus neoformans/C. gattii complex. We compared the clinical, biological, and antifungal susceptibility profiles of isolates from HIV-Infected Patients (HIVIP) with C. neoformans (Cn) versus C. curvatus/C. laurentii (CC/Cl) meningitis.

Methods: Comparative analytical study were conducted. Apart from patients' clinical data, the following analysis were performed and the results were compared in both groups: biochemical examination, cryptococcal antigen test, India ink staining, and culture on Cerebral Spinal Fluid (CSF), strains identification by mass spectrometry, ITS sequencing, PCR serotyping and antifungal susceptibility. The main outcome variable was the "species of Cryptococcus identified", which was compared to other variables of the same type using the Pearson Chi-square test or the Fisher exact test.

Results: A total of 23 (79.3\%) Cn meningitis cases versus 6 (20.7\%) Cc/Cl meningitis were retained. Cn meningitis was more frequently associated with headache (100\% vs 50\%, $p=0.005)$ than $\mathrm{C} / \mathrm{Cl}$ meningitis and meningeal signs were more frequent in $\mathrm{Cn}$ infected patients. Biologically, hypoglycorrhachia and low $\mathrm{CD}_{4}$ count were more observed in $\mathrm{Cn}$ group ( $90 \%$ vs $20 \%$ of patients, $p=0.01 ; 45.6$ vs 129.8 cells $/ \mu \mathrm{L}, p=0.02$, respectively). A higher proportion of Cn strains (91.3\%) showed a low Minimum Inhibitory Concentration (MIC) (<8 mg/L) for fluconazole compared to Cc/Cl strains (66.7\%). Also, Cc/Cl strains resistant to 5 -flucytosine and amphotericin B were found in $16.7 \%$ of cases for each of the two antifungal agents. Cryptococcus detection by routine analysis (India ink, culture, and antigens) was better for Cn samples than $\mathrm{C} / \mathrm{Cl}$. Except ITS sequencing, which identified all strains of both groups, mass spectrometry and serotyping PCR identified Cn strains better than C $/ C l(100 \%$ vs $80 \%, p=0.1 ; 100 \%$ vs 0\%, $p<0.0001$, respectively). After treatment with amphotericin B, 5-flucytosine, and fluconazole in both groups, the outcome was similar.
\end{abstract}

Conclusions: Clinical presentation of $\mathrm{Cn}$ meningitis is certainly more severe than that of $\mathrm{Cc} / \mathrm{Cl}$ meningitis, but $\mathrm{Cc}$ $\mathrm{Cl}$ infection should be considered in the management of HIVIP with meningeal syndrome because of the diagnostic

\footnotetext{
*Correspondence: bive.zono@unikin.ac.cd

${ }^{1}$ Molecular Biology Service, Department of Basic Sciences, Faculty

of Medicine, University of Kinshasa, Kinshasa, Democratic Republic

of Congo

Full list of author information is available at the end of the article
}

(C) The Author(s) 2021. Open Access This article is licensed under a Creative Commons Attribution 4.0 International License, which permits use, sharing, adaptation, distribution and reproduction in any medium or format, as long as you give appropriate credit to the original author(s) and the source, provide a link to the Creative Commons licence, and indicate if changes were made. The images or other third party material in this article are included in the article's Creative Commons licence, unless indicated otherwise in a credit line to the material. If material is not included in the article's Creative Commons licence and your intended use is not permitted by statutory regulation or exceeds the permitted use, you will need to obtain permission directly from the copyright holder. To view a copy of this licence, visit http://creativecommons.org/licenses/by/4.0/. The Creative Commons Public Domain Dedication waiver (http://creativeco mmons.org/publicdomain/zero/1.0/) applies to the data made available in this article, unless otherwise stated in a credit line to the data. 
difficulty and the high MICs of antifungal agents required for the treatment of meningitis due to these cryptococcal species.

Keywords: Cryptococcus neoformans, Cryptococcus curvatus, Cryptococcus laurentii, Meningitis, HIV, Clinical characteristic, Biological characterization, Kinshasa, DRC

\section{Background}

In clinical pathology, two species of Cryptococcus spp. are mainly involved in Meningeal Cryptococcosis (MC), namely Cryptococcus neoformans $(\mathrm{Cn})$ and $\mathrm{C}$. gattii $(C g)$ [1]. The interest of Cryptococcus spp. identification down to species level is based on the fact that some species such as $C$. gattii cause infections that require a much more intensive therapeutic approach than those caused by C. neoformans [2]. Non-neoformans and non-gattii species have long been considered as saprophytes and non-pathogenic to humans. However, the prevalence of opportunistic infections due to these species (involving the skin, lungs, bloodstream, and central nervous system) has been increasing all over the world in recent years. Among these species, $C$. laurentii and C. albidus are implicated in $80 \%$ of cases [3, 4]. Also in rare cases, $C$. curvatus has been incriminated in peritoneal and myeloradicular infections in hospital settings [5-7]. Few studies are comparing different characteristics of infections caused by the $C$. neoformans/C. gattii complex versus those due to non-neoformans and non-gattii species in HIV-Infected Patients (HIVIP).

We hypothesized that the clinical and biological characteristics of HIVIP with meningitis due to $\mathrm{Cn}$ could be different from those of patients infected by $C$. curvatus/C. laurentii $(\mathrm{Cc} / \mathrm{Cl})$. The objective of this study was to compare the clinical, biological, and therapeutic characteristics, antifungal susceptibility profile of strains isolated from HIVIP with $\mathrm{Cn}$ versus $\mathrm{Cc} / \mathrm{Cl}$ meningitis. In addition, the molecular identification of the strains was also compared.

\section{Methods}

\section{Study design, patients, and samples}

This is a comparative analytical study. The patients were drawn from a cross-sectional study conducted in Kinshasa (Democratic Republic of Congo) from 1st February 2019 to 29th February 2020, having included HIVIP with the meningeal syndrome in the hospitals with expertise in the management of advanced HIV-infection, namely: Centre Hospitalier Mère et Enfant de NGABA (CHME NGABA), Centre Médical et Evangélique Révérend LUYINDU (CME LUYINDU) and Centre Hospitalier Roi Baudouin $1^{\text {er }}\left(\mathrm{CHRB} 1^{\mathrm{er}}\right)$. The overall data from this study have not yet been published. In these public hospitals supported by Doctors without Borders-Belgium (MSF), lumbar puncture in HIVIP has specific indications. It was performed in each patient presenting meningeal signs or neurological symptoms including headache, epilepsy, lethargy, or cognitive deficits and/or in all HIVIP with a $\mathrm{CD}_{4}$ LT number $<100$ cells $/ \mu \mathrm{L}$ with cryptococcal antigenemia. Diagnostic confirmation of cryptococcosis is based on the blood cryptococcal antigen detection for serum cryptococcosis or the Cerebral Spinal Fluid (CSF) cryptococcal antigen detection for MC. In the present study, routine diagnostic confirmation was extended. Thus, MC diagnosis was based on the detection in the patient CSF, of cryptococcal antigens and/or the yeasts by India ink staining and/or positive culture.

\section{Initial analysis}

The detection of Cryptococcal Antigens (CrAg) was carried out in the CSF of each patient, using the CrAg LFA IMMY test (Immuno-mycologic, Norman, OK, USA). Direct staining with India ink on the CSF was also carried out to reveal the cryptococcal capsule and the CSF was cultured on Sabouraud Dextrose Agar-Chloramphenicol medium (SDA-C, bioMérieux, France) at $30{ }^{\circ} \mathrm{C}$ for 48 to $72 \mathrm{~h}$. Proteinorachia was determined by the Pandy test, a previously described qualitative test [8].

\section{Identification by MALDI-TOF MS}

The MALDI-TOF MS (Matrix-Assisted Laser Desorption Ionization Time-Of-Flight Mass Spectrometry, Bruker Daltonics $\mathrm{GmbH}$, Germany), was used for the identification of all fungal strains at $\mathrm{CHU}$ de Liège (Belgium). From the culture on SDA-C, an extended direct deposit was performed by adding $1 \mu \mathrm{L}$ of $70 \%$ formic acid to the sample on a MALDI target plate (MSP 96 BC ground steel target; Bruker Daltonics). Then, $1 \mu \mathrm{L}$ of saturated cyano-4-hydroxycinnamic acid solution (HCCA matrix; Bruker Daltonics) was added. A Bruker Bacterial Test Standard (BTS255343; Bruker Daltonics) was used for instrument calibration. Each microorganism tested was spotted twice on the same target slide. Measurement was performed with MALDI Flex control V3.4 (Bruker Daltonics) following the settings suggested by the manufacturer using automated collecting spectra. The spectra of each duplicated spot were compared with those in the reference library (BD 8326 or version V 9.0) [9]. The following score was considered for the identification of the fungal species: MS Score $\geq 1.5$ and the three first results 
identical and consistent with the appearance of the colonies on agar.

\section{Molecular analysis DNA extraction}

Genomic DNA was extracted from the fresh 24-h cultures on SDA-C using the NucleoSpin blood quick pure kit (Macherey-Nagel, Duren, Germany). Two preliminary steps were added to the manufacturer's protocol, namely bead-beating, and thermal shock. In a $2 \mathrm{~mL}$ tube containing $0.5 \mathrm{~mm}$ glass beads (Roche Diagnostics $\mathrm{GmbH}$, Penzberg, Germany), colonies were mixed with $350 \mu \mathrm{L}$ lysis buffer (Promega Corporation, USA). The mixture was vortexed five times at 6000 vibrations per minute for $40 \mathrm{~s}$ (bead-beating). Between each pass, the tube was cooled between -20 and $1{ }^{\circ} \mathrm{C}$ for $30 \mathrm{~s}$ in a Nalgene microtube cooler container (Dutscher, France) (thermal shock).

\section{ITS sequencing}

The rRNA ITS2 region was amplified using the ITS86 forward primer 5'GTGAATCATCGAATCTTTGAA $3^{\prime}$ and ITS4 reverse primer 5'TCCTCCGCTTATTGA TATGC 3' [10]. PCR was done on a classical thermocycler (Thermo Hybaid, Thermo Scientific). Purification of PCR products was then performed using the Exosap IT technique (Amersham, GE Healthcare Europe GmbH, Belgium). Bidirectional sequence data were generated after purification using the BigDye terminator sequencing kit (Applied Biosystems, Life Technologies, Belgium). Sequenced products were finally purified using the kit clean Seq Agencourt (Beckman Coulter Life Science). The sequencing was done on the automate ABI 3500/3500XL (Applied Biosystem, Life Technologies). Sequences were edited using the ABI Sequence Scanner V.1.0 software (Applied Biosystems, Life Technologies). Sequences generated by the software were then compared to the CBS database by using BIOLOMICSNET software (http://www.cbs.knaw.nl/collections/Biolo MICSSequences.aspx), which comprises several databases including Genbank. Only results that repeated the same identification at least three times and had a similarity score greater than $95 \%$ were considered valid.

\section{Serotyping PCR}

A classical serotyping PCR, which has been designed for $\mathrm{Cn} / \mathrm{Cg}$ species complex, was performed according to the protocol described by Ito-Kuwa et al. [11] Two primer pairs of the LAC1 gene and one primer pair of the CAP64 gene were used.

\section{Antifungal susceptibility testing}

Determination of Minimal Inhibitory Concentration (MIC) was done according to the EUCAST E.Def 7.3.1 procedure [12]. Inoculum suspensions of 0.5 McFarland standard were prepared and diluted 1:10 with sterile distilled water (Sensititre tm demineralized water, Thermo Scientific, USA). The final concentration range was $0.008-8 \mathrm{mg} / \mathrm{L}$ for amphotericin $\mathrm{B}$ (after inoculation) and $0.06-64 \mathrm{mg} / \mathrm{L}$ for 5 -flucytosine and fluconazole. The reading of the MIC50 value (drug concentration resulting in inhibition of $50 \%$ of microorganisms) for 5-flucytosine and fluconazole, and MIC90 for amphotericin $\mathrm{B}$, was done according to the described recommendations using a visual and automated reading at $405 \mathrm{~nm}$ with a Multiscan FC spectrophotometer (Thermo Scientific, MA, USA). Candida parapsilosis ATCC 22019 and Candida krusei ATCC 6258 were used as the quality control strains for the tests. The interpretation criteria for amphotericin B were those defined in EUCAST (European Committee on Antimicrobial Susceptibility Testing) version 10.0 Breakpoint tables: susceptible, MIC $\leq 1 \mathrm{mg} / \mathrm{L}$; Resistant, MIC $>1 \mathrm{mg} / \mathrm{L}$. Being not defined in the EUCAST tables, the interpretation of fluconazole and 5-flucytosine was based on the criteria published by the Clinical Laboratory Standards Institute (CLSI) as follows: for fluconazole, sensitive if $\mathrm{MIC} \leq 8 \mathrm{mg} / \mathrm{L}$; dose-dependent sensitive if MIC between 16 and $32 \mathrm{mg} / \mathrm{L}$; resistant if $\mathrm{MIC} \geq 64 \mathrm{mg} / \mathrm{L}$; for flucytosine, sensitive if $\mathrm{MIC} \leq 4 \mathrm{mg} / \mathrm{L}$; intermediate if MIC between 8 and $16 \mathrm{mg} / \mathrm{L}$; resistant, if $\mathrm{MIC} \geq 32 \mathrm{mg} / \mathrm{L}[13$, 14].

\section{Statistical analysis}

The analysis were carried out using R-Cmdr version 2.6-1 (R Foundation for Statistical Computing, Vienna, Austria). Missing data were considered completely random and the available data were analyzed. The continuous variables were summarised as mean \pm standard deviation and compared using Student's t-test. The proportions and their respective 95\% confidence intervals were calculated for the categorical data. The main outcome variable was the "species of Cryptococcus identified", which was compared to other variables of the same type using the Pearson Chi-square test or the Fisher exact test if the expected values were less than 5 . All tests were two-tailed and a $p<0.05$ was considered statistically significant.

\section{Results}

\section{Study population and clinical data}

Of the 29 patients included for cryptococcal meningitis with positive culture on CSF, six (20.7\%; 95\% CI 6.9$34.5 \%$ ) were infected by non-neoformans and non-gattii Cryptococcus species. In five cases, it was C. curvatus, and in one case C. laurentii.

The demographic and clinical characteristics of patients infected by each group species are presented in Table 1 . 
Table 1 Demographic and clinical characteristics of HIVinfected patients with C. neoformans versus C. curvatus/C. laurentii meningitis

\begin{tabular}{|c|c|c|c|}
\hline \multirow[t]{2}{*}{ Variable } & \multicolumn{2}{|c|}{ Cryptococcal species } & \multirow[t]{2}{*}{$p$} \\
\hline & $\begin{array}{l}\text { C. neoformans } \\
n^{a}(\%)^{b}\end{array}$ & $\begin{array}{l}\text { C. } \\
\text { curvatus/C. } \\
\text { laurentii } \\
\mathrm{n}^{\mathrm{a}}(\%)^{\mathrm{b}}\end{array}$ & \\
\hline \multicolumn{4}{|l|}{ Demographic characteristics } \\
\hline Age, mean (year) $\pm S D$ & $36.7 \pm 11 \cdot 3$ & $38.3 \pm 9.1$ & 0.1 \\
\hline Female sex & $15(65.2)$ & $4(66.7)$ & 1 \\
\hline Marital status & & & 0.56 \\
\hline Single & $8(34.8)$ & $3(60.0)$ & \\
\hline Married/free union & $10(43.5)$ & $2(40.0)$ & \\
\hline $\begin{array}{l}\text { Divorced/separated/wid- } \\
\text { owed }\end{array}$ & $5(21.7)$ & 0 & \\
\hline Clinical stage of HIV (WHO) & & & 0.19 \\
\hline Stage III & 0 & $1(20.0)$ & \\
\hline Stage IV & $21(100)$ & $4(80.0)$ & \\
\hline Antiretroviral therapy (ART) & $20(87.0)$ & $3(50.0)$ & 0.08 \\
\hline \multicolumn{4}{|l|}{ Clinical signs } \\
\hline Headache & $23(100)$ & $3(50.0)$ & 0.005 \\
\hline Fever & $18(78.0)$ & $2(33.3)$ & 0.05 \\
\hline Weight loss & $16(69.6)$ & $2(33.3)$ & 0.16 \\
\hline Disorder of consciousness & $11(47.8)$ & 0 & 0.05 \\
\hline Meningeal signs & $7(30.4)$ & 0 & 0.28 \\
\hline Memory impairment & $6(26.1)$ & 0 & 0.29 \\
\hline Convulsions & $4(17.4)$ & 0 & 0.55 \\
\hline Dizziness & $4(17.4)$ & $1(16.7)$ & 1 \\
\hline Visual disturbances & 0 & $2(33.3)$ & 0.03 \\
\hline Hemiplegia & 0 & $1(16.7)$ & 0.2 \\
\hline Neck pain & $1(4.3)$ & 0 & 1 \\
\hline Facial paralysis & 0 & $1(16.7)$ & 0.2 \\
\hline Mean temperature $\left({ }^{\circ} \mathrm{C}\right) \pm \mathrm{SD}$ & $36.8 \pm 0.8$ & $36.1 \pm 1.3$ & 0.08 \\
\hline Duration of symptoms & $18.3 \pm 14.7$ & $19.3 \pm 9.4$ & 0.8 \\
\hline
\end{tabular}

${ }^{\text {a }}$ With available data

${ }^{b}$ Percentage of columns calculated for each group

Compared to $\mathrm{Cc} / \mathrm{Cl}$ infected patients, $\mathrm{Cn}$ infected patients were most susceptible to headache on admission $(100 \%$ vs $50 \%, p=0.005)$. Remarkably, the following neuromeningeal signs were only found in $\mathrm{Cn}$ infected patients: consciousness disorders (47.8\%), meningeal signs (30.4\%), cognitive deficits (26.1\%), and convulsions (17.4\%). The distribution of age, sex, and marital status in the two groups of patients were similar. While all patients infected with $\mathrm{Cn}$ were in the terminal stage of HIV infection, $20 \%$ of patients with $\mathrm{Cc} / \mathrm{Cl}$ were classified in stage III, before cryptococcosis diagnosis has been established (not significant). Approximately 18.3 and 19.3 days were the average time elapsed between the appearance of the
Table 2 HIV biological data of patients with meningitis due to $C$. neoformans versus C. curvatus/C. laurentii

\begin{tabular}{llll}
\hline Variable & \multicolumn{2}{l}{ Cryptococcal species } & $p$ \\
\cline { 2 - 3 } & $\begin{array}{l}\text { C. neoformans } \\
\mathbf{n}^{\mathbf{a}}(\%)^{\mathbf{b}}\end{array}$ & $\begin{array}{l}\text { C. curvatus/C. laurentii } \\
\mathbf{n}^{\mathbf{a}}(\%)^{\mathbf{b}}\end{array}$ & \\
\hline $\mathrm{CD}_{4}($ cells $/ \mu \mathrm{L}) \pm \mathrm{SD}$ & $45.6 \pm 40.8$ & $129.8 \pm 142.1$ & 0.02 \\
Viral load (copies $/ \mathrm{mL})$ & & & 0.6 \\
Undetectable $(<40)$ & $1(25.0)$ & 0 & \\
Low $\left(40-10^{3}\right)$ & $1(25.0)$ & 0 & \\
High $\left(10^{3}-10^{5}\right)$ & $2(50.0)$ & 0 & \\
Very high $\left(\geq 10^{5}\right)$ & 0 & $1(100)$ & \\
\hline${ }^{\text {a With available data }}$ & & &
\end{tabular}

first symptoms and the diagnosis of meningitis in the patients' group with $\mathrm{Cn}$ versus $\mathrm{Cc} / \mathrm{Cl}$ meningitis, respectively. Comparison of clinical features in $\mathrm{Cn}$ and $\mathrm{Cc} / \mathrm{Cl}$ infected patients respectively showed marked differences in fever $(78.0 \%$ vs $33.3 \%)$, weight loss $(66.9 \%$ vs $33.3 \%)$, dizziness $(17.4 \%$ vs $16.8 \%)$, hemiplegia ( $0 \%$ vs $16.7 \%)$, neck pain ( $4.3 \%$ vs $0 \%$ ) and facial paralysis ( $0 \%$ vs $16.7 \%)$.

\section{HIV biological data of the patients}

The HIV biological analysis results of the patients are presented in Table 2. The mean $\mathrm{CD}_{4}$ cell count was 45.6 cells $/ \mu \mathrm{L}$ in the $C n$ infected patients, which was significantly lower than in the $\mathrm{Cc} / \mathrm{Cl}$ group $(129.8$ cells/ $\mu \mathrm{L}$, $p=0.02$ ). While $50 \%$ of $\mathrm{Cn}$ meningitis patients had a moderately high viral load $\left(10^{3}-10^{5}\right.$ copies $\left./ \mathrm{mL}\right)$, the only viral load available for the patients infected with $\mathrm{Cc} / \mathrm{Cl}$ was very high $\left(>10^{5}\right.$ copies $\left./ \mathrm{mL}\right)$.

\section{CSF analysis characteristics CSF analysis characteristics patients}

All patients infected with $\mathrm{Cc} / \mathrm{Cl}$ had clear CSF versus $13 \%$ of cloudy appearance in $\mathrm{Cn}$ group patients. In both groups, the majority of patients had a very high opening pressure during a lumbar puncture $(75 \%$ vs $66.6 \%, C n$ and $\mathrm{Cc} / \mathrm{Cl}$ respectively). Approximately $90 \%$ of patients with $\mathrm{Cn}$ meningitis had significantly low glycorrachia ( $<50 \mathrm{mg} / \mathrm{dL}$ ) compared to $20 \%$ of $\mathrm{Cc} / \mathrm{Cl}$ infected patients $(p=0.01)$. Accordingly, the mean value of glycorrachia was lower in the $C n$ infected group $(46.7 \pm 11.2 \mathrm{mg} / \mathrm{dL})$ than in the $\mathrm{Cc} / \mathrm{Cl}$ group patients $(66.1 \pm 22.5 \mathrm{mg} / \mathrm{dL}$, $p=0.04)$. Sixty per cent of patients infected with $\mathrm{Cc} / \mathrm{Cl}$ had a positive qualitative proteinorachia (Pandy test), while $56.2 \%$ of patients infected with $C n$ had a negative test $(p=0.6)$. No significant difference was noted between the mean cytorrachia in the $\mathrm{Cn}$ patients group versus those infected with $\mathrm{Cc} / \mathrm{Cl}$. Nearly $33.3 \%$ of $\mathrm{Cn}$ infected patients had a predominantly lymphocytic 
cytorrachia compared to $50 \%$ in the other group. While all the study cases had positive cultures $(100 \%$ in both groups), three $C$. curvatus strains had atypical presentation with reddish hues within the colonies (Fig. 1). Only $18 \mathrm{Cn}$ (out of 23) and two $\mathrm{Cc} / \mathrm{Cl}$ (out of six) samples were positive on direct India ink staining. Similarly for the CrAg test in CSF, 95.7 vs $66.7 \%$ were positive in each group, $\mathrm{Cn}$ and $\mathrm{Cc} / \mathrm{Cl}$ respectively. $\mathrm{CSF}$ analysis characteristics are shown in Table 3.

\section{Species identification}

All strains (100\%) of $C n$ were identified by ITS sequencing and then by mass spectrometry. In comparison, $20 \%$ of the $\mathrm{Cc} / \mathrm{Cl}$ strains were not identified by mass spectrometry although they were all identified by ITS sequencing. Between the same species, slight differences in ITS sequences were noted among both $\mathrm{Cn}$ and $\mathrm{Cc}$ isolates. Besides $\mathrm{Cl}$ isolate which was unidentified by MALDI-TOF MS, one $C c$ isolate was also unidentified, and the same isolate had a slightly different post multiplex PCR electrophoretic profile than others of the same species, namely the absence of the $1100 \mathrm{pb}$ band (lane 5).

The difference in MALDI-TOF MS identification between the two groups was not significant; although the spectral profiles were very different. By serotyping multiplex PCR, the $\mathrm{Cc} / \mathrm{Cl}$ strains were not identifiable, whereas the $\mathrm{Cn}$ strains were all identified as serotype A. The $\mathrm{Cc} / \mathrm{Cl}$ strains had an electrophoretic profile that was not comparable to the reference profile of the $\mathrm{Cn}$ species commonly serotyped by this technique (Fig. 2). Apart from this, four out of five $C c$ isolates had a similar electrophoretic profile and one was slightly different from the
Table 3 CSF analysis characteristics of HIV-infected patients with C. neoformans versus C. curvatus/C. laurentii meningitis

\begin{tabular}{|c|c|c|c|}
\hline \multirow[t]{2}{*}{ Variable } & \multicolumn{2}{|c|}{ Cryptococcal species } & \multirow[t]{2}{*}{$p$} \\
\hline & $\begin{array}{l}\text { C. neoformans } \\
\mathrm{n}^{\mathrm{a}}(\%)^{\mathrm{b}}\end{array}$ & $\begin{array}{l}\text { C. } \\
\text { curvatus/C. } \\
\text { laurentii } \\
\mathrm{n}^{\mathrm{a}}(\%)^{\mathrm{b}}\end{array}$ & \\
\hline The clear appearance of CSF & $20(87.0)$ & $6(100)$ & 1 \\
\hline $\begin{array}{l}\text { Mean opening pressure (cm of } \\
\text { water) }\end{array}$ & $30.0 \pm 7.6$ & $28.3 \pm 7.6$ & 1 \\
\hline CSF opening pressure $\mathrm{cm}$ of water) & & & 1 \\
\hline Normal $(<20)$ & $1(12.5)$ & 0 & \\
\hline High (20-30) & $1(12.5)$ & $1(33.3)$ & \\
\hline Very high $(\geq 30)$ & $6(75.0)$ & $4(66.6)$ & \\
\hline Glycorrachia $(\mathrm{mg} / \mathrm{dL}) \pm S D$ & $46.7 \pm 11.2$ & $66.1 \pm 22.5$ & 0.04 \\
\hline Glycorrachia (mg/dL) & & & 0.01 \\
\hline $\operatorname{Low}(\leq 50)$ & $9(90.0)$ & $1(20.0)$ & \\
\hline Normal (50-60) & 0 & $1(20.0)$ & \\
\hline $\operatorname{High}(\geq 60)$ & $1(10.0)$ & $3(60.0)$ & \\
\hline Positive pandy & $7(43.8)$ & $3(60.0)$ & 0.63 \\
\hline Cytorrachia (cells $/ \mathrm{mm}^{3}$ ) $\pm \mathrm{SD}$ & $41.52 \pm 51.6$ & $15.8 \pm 23.5$ & 0.25 \\
\hline Lymphocytic cytorrachia & $5(33.3)$ & $1(50.0)$ & 1 \\
\hline Positive culture on CSF & $23(100)$ & $6(100)$ & 1 \\
\hline Positive India ink on CSF & $18(78.3)$ & $2(33.3)$ & 0.06 \\
\hline CrAg present on CSF & $22(95.7)$ & $4(66.7)$ & 0.09 \\
\hline
\end{tabular}

${ }^{\text {a }}$ With available data

${ }^{\mathrm{b}}$ Percentage of columns calculated for each group

others. The difference in serotype identification was statistically significant in both groups $(p<0.0001)$. The comparison of identification results is presented in Table 4.

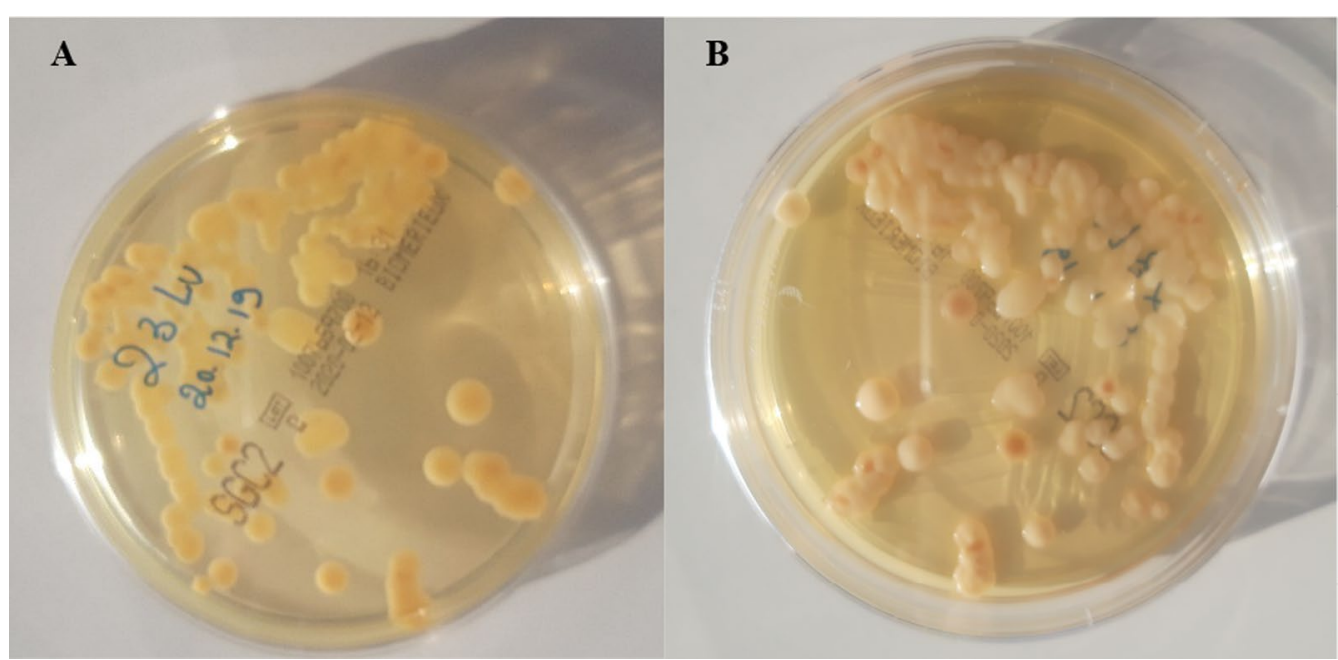

Fig. 1 Beige mucoid colonies with reddish hues of C. curvatus on SDA-Chloramphenicol after 48 -h incubation at $30^{\circ} \mathrm{C}$ is shown from the top (A) and the bottom (B) of the plate 


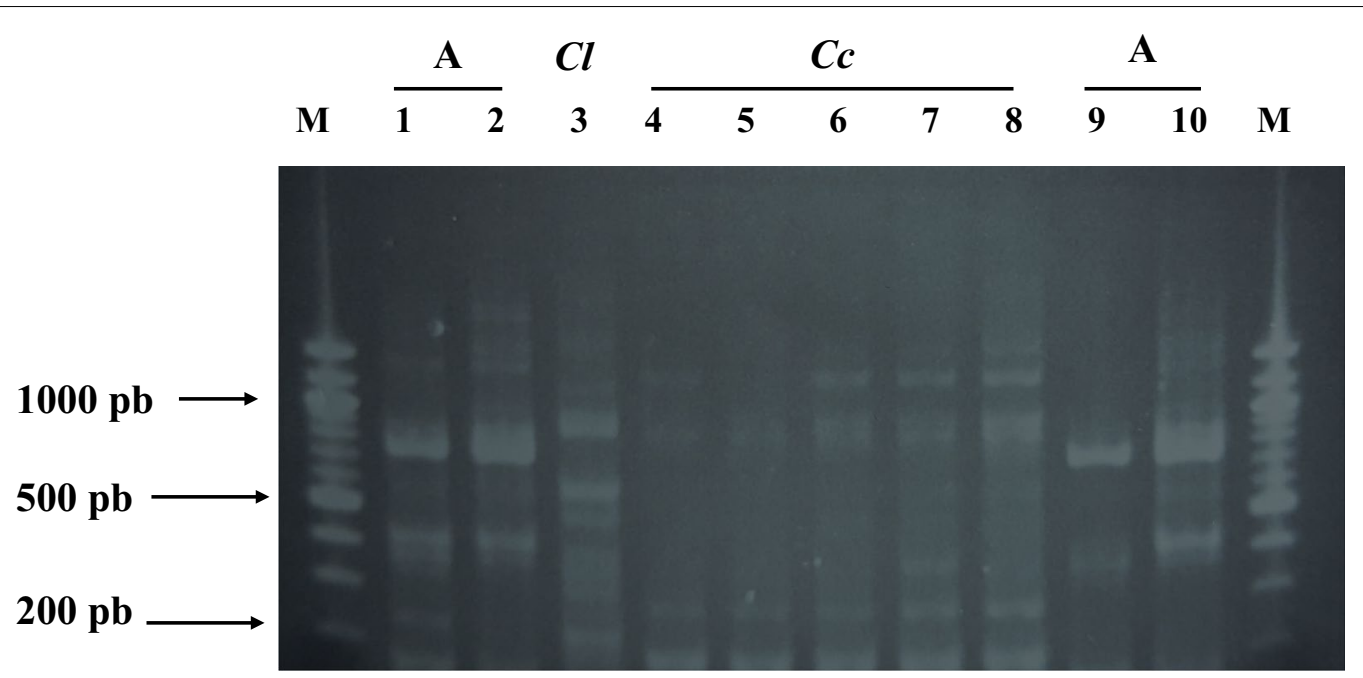

Fig. 2 DNA fragments of $C n$ and $C C / C l$ isolates obtained after multiplex PCR amplification of LAC1 and CAP64 genes. Lanes 1, 2, 9 and, 10, Cn serotype A profile. Lane 3, isolate of $\mathrm{Cl}$ and lanes 4-7 and 8, isolates of Cc. M, molecular weight marker. The $\mathrm{Cc} / \mathrm{Cl}$ isolates thus gave DNA bands of different sizes and numbers from the reference profiles. While the $\mathrm{C} n$ isolates had given the characteristic major band of serotype A of about $760 \mathrm{bp}$ and a small band of $420 \mathrm{bp}$, the Cc isolates had the first band of about $1100 \mathrm{bp}$ and a second of $800 \mathrm{bp}$, and the $\mathrm{Cl}$ isolates had a band of about $900 \mathrm{bp}$ and another of about $600 \mathrm{bp}$, profiles that don't match with those of different serotypes of the $\mathrm{Cn} / \mathrm{Cg}$ complex

Table 4 Identification of $\mathrm{Cn}$ versus $\mathrm{C} / \mathrm{Cl}$ by MALDI-TOF MS and PCR serotyping compared to ITS sequencing

\begin{tabular}{|c|c|c|c|}
\hline \multirow[t]{2}{*}{ Variable } & \multicolumn{2}{|c|}{ Cryptococcal species $^{a}$} & \multirow[t]{2}{*}{$p$} \\
\hline & $\begin{array}{l}\text { C. neoformans } \\
\text { n (\%) }\end{array}$ & $\begin{array}{l}\text { C. } \\
\text { curvatus/C. } \\
\text { laurentii } \\
\mathrm{n}(\%)\end{array}$ & \\
\hline MALDI-TOF MS & & & 0.1 \\
\hline Cryptococcus spp. & $23(100)$ & $4(80)$ & \\
\hline Not identified & 0 & $2(20)$ & \\
\hline Multiplex PCR serotyping & & & $<0.0001$ \\
\hline Serotype A & $23(100)$ & 0 & \\
\hline Non identifiable serotype & 0 & $6(100)$ & \\
\hline
\end{tabular}

a ITS sequencing identification

\section{Antifungal susceptibility of patients' strains}

About $91.3 \%$ of $C n$ group strains (21 of 23) had a $\mathrm{MIC} \leq$ of $8 \mathrm{mg} / \mathrm{L}$ for fluconazole, compared to $66.7 \%$ in $\mathrm{Cc} / \mathrm{Cl}$ group (four of six). In both groups, the proportion of strains susceptible to 5-flucytosine were almost similar $(82.6 \%$ and $83.3 \%, \mathrm{Cn}$ and $\mathrm{Cc} / \mathrm{Cl}$ strains respectively) and one strain in the $\mathrm{Cc} / \mathrm{Cl}$ group was resistant (16.7\%). While all $\mathrm{Cn}$ strains were sensitive to amphotericin $\mathrm{B}, 16.7 \%$ of $\mathrm{Cc} / \mathrm{Cl}$ strains were resistant. The only $\mathrm{Cl}$ isolate that was unidentified by MALDI-TOF MS was resistant to both flucytosine and amphotericin B. In vitro susceptibility profile of strains against each of the three antifungal agents tested was not statistically different in the two groups (Fig. 3).

\section{Treatment and outcome}

Table 5 shows the outcome of Cryptococcus-infected patients after treatment by antifungal agents. Treatment with liposomal amphotericin B (3 $\mathrm{mg} / \mathrm{kg} /$ day for 7 days) combined with 5 -flucytosine $(100 \mathrm{mg} / \mathrm{kg}$ taken four times daily for 7 days) in the induction phase, followed by fluconazole ( $800 \mathrm{mg} /$ day for 8 weeks) for the consolidation phase was administered to $95.7 \%$ of patients who were hospitalized after MC diagnosis. One (33.3\%) of the Cc/ $\mathrm{Cl}$ infected patients was treated with fluconazole alone (800 mg/days) due to lack of meningeal location confirmation. Patients infected with $\mathrm{Cc} / \mathrm{Cl}$ remained hospitalized for 12.4 vs 9.9 days in the $C n$ group (not significant). Thirteen out of $23 \mathrm{Cn}$ group patients (56.5\%) had a pejorative clinical course (death, status quo, and discharge against medical advice or transfer due to complications) versus $16.7 \%$ in the $\mathrm{Cc} / \mathrm{Cl}$ group (not significant).

\section{Discussion}

Cryptococcal meningitis has been described as an opportunistic infection in HIVIP, mainly caused by the $\mathrm{Cn}$ / Cg species complex $[15,16]$. However, non-neoformans and non-gattii Cryptococcus species have recently been isolated in cryptococcosis both in immunosuppressed and immunocompetent patients. $C$. curvatus and $C$. laurentii are among these species $[3,6,17]$. While $C$. laurentii has already been associated with bloodstream, 


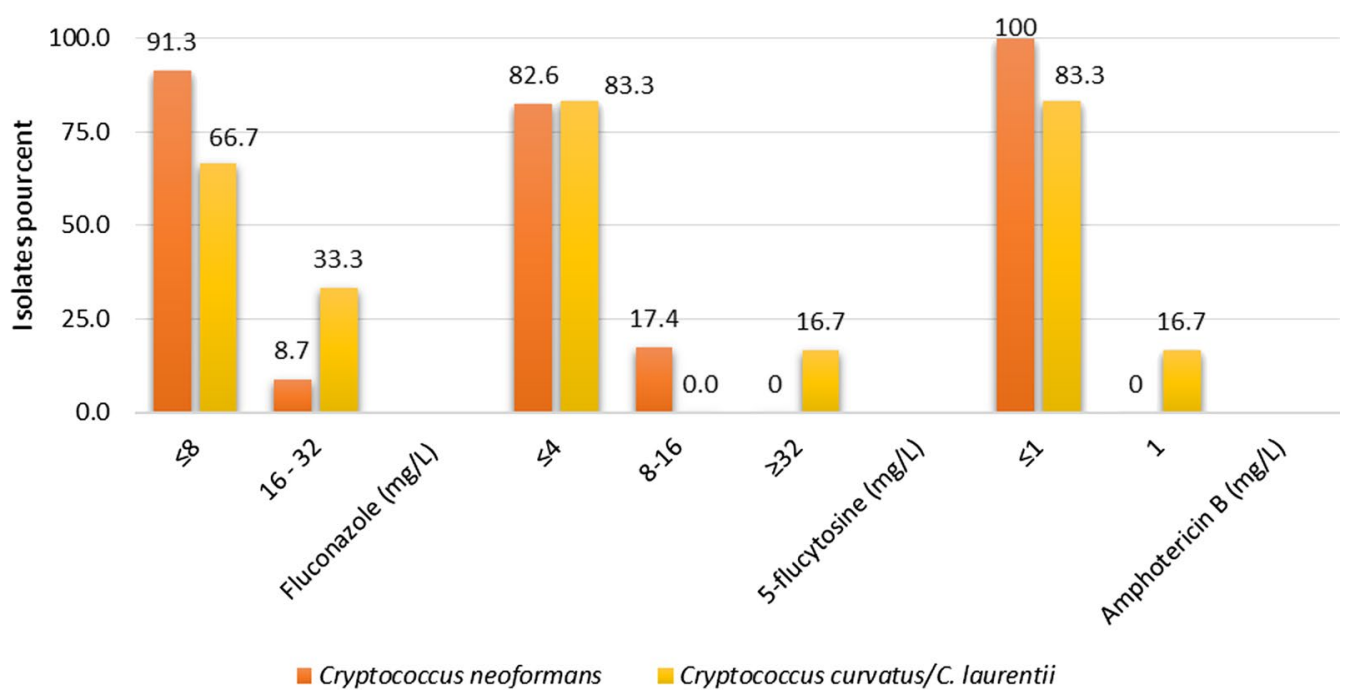

Fig. 3 Comparative susceptibility of $\mathrm{Cn}$ versus $\mathrm{C} / \mathrm{Cl}$ strains to usual antifungal agents by EUCAST procedure

Table 5 Treatment and outcome of patients with C. neoformans versus C. curvatus/C. laurentii meningitis

\begin{tabular}{|c|c|c|c|}
\hline \multirow[t]{2}{*}{ Variable } & \multicolumn{2}{|c|}{ Cryptococcal species } & \multirow[t]{2}{*}{$p$} \\
\hline & $\begin{array}{l}\text { C. neoformans } \\
\mathrm{n}^{\mathrm{a}}(\%)^{\mathrm{b}}\end{array}$ & $\begin{array}{l}\text { C. } \\
\text { curvatus/C. } \\
\text { laurentii } \\
\mathrm{n}^{\mathrm{a}}(\%)^{\mathrm{b}}\end{array}$ & \\
\hline Scheme of antifungal agents & & & 0.09 \\
\hline $\mathrm{AFF}^{\mathrm{C}}$ & $22(95.7)$ & $4(66.7)$ & \\
\hline Fluconazole & 0 & $1(33.3)$ & \\
\hline Average hospital stay (day) & $9.9 \pm 6.01$ & $12.4 \pm 5.27$ & 0.65 \\
\hline Therapeutic outcome & & & 0.16 \\
\hline Good $^{d}$ & $10(43.5)$ & $5(83.3)$ & \\
\hline $\mathrm{Bad}^{\mathrm{e}}$ & $13(56.5)$ & $1(16.7)$ & \\
\hline
\end{tabular}

${ }^{\text {a }}$ With available data

${ }^{b}$ Percentage of columns calculated for each group

${ }^{c}$ Amphotericin B + 5-flucytosine + fluconazole

${ }^{d}$ Recovery and discharge from hospital

e Death, status quo, discharge against medical advice or transfer due to complications

neuromeningeal, pulmonary, cutaneous, and peritoneal infections $[3,4,18-20]$, C. curvatus has very rarely been implicated in human infections, mainly in peritoneal and myeloradicular infections [5-7].

Of the 29 Cryptococcus spp. meningitis patients with positive culture included in the present study, six (20.7\%, 95\% CI 6.9-34.5\%) had non-neoformans and non-gattii Cryptococcus species, including five cases of C. curvatus and one case of $C$. laurentii. To our best knowledge, this study is the first to compare the biological and clinical characteristics of Cryptococcus spp. meningitis induced by these two species groups in the sub-Saharan African region. Globally, $79.3 \%$ were identified as $\mathrm{Cn}$ and $20.7 \%$ as $\mathrm{Cc} / \mathrm{Cl}$. A similar prevalence of non-neoformans and non-gattii Cryptococcus infections was reported in three states of the United States of America (USA) in 2020 and during the same study, C. laurentii, C. liquefaciens, and C. magnus were considered as pathogenic [21].

Patients with $\mathrm{Cn}$ were most susceptible to headache on admission than patients with $\mathrm{Cc} / \mathrm{Cl}$ and most neuromeningeal signs were also found preferentially in $\mathrm{Cn}$ patients. The distribution of these signs could suggest a more virulent trait of $\mathrm{Cn}$ strains compared to $\mathrm{Cc} / \mathrm{Cl}$ strains. The main virulence factors of the Cryptococcus genus i.e. presence of the polysaccharide capsule, resistance to high temperatures $\left(>37^{\circ} \mathrm{C}\right)$, and the activity of the laccase enzyme, have been identified for the $\mathrm{Cn}$ complex as well as for the non-neoformans and non-gattii Cryptococcus species. However, the laccase enzyme activity was described as lower for non-neoformans and non-gattii Cryptococcus species compared to that of the $\mathrm{Cn}$ [7]. This could explain the more severe clinical presentation of the $\mathrm{Cn}$ group patients compared to $\mathrm{Cc} / \mathrm{Cl}$ group, as described also by Cano et al. [21].

As mentioned above, most species of the genus Cryptococcus possess a polysaccharide capsule and share the same antigenic determinants with minor differences, and are therefore likely to be detected by India ink staining and/or have antigenic activity detectable by diagnostic tests [22]. Nevertheless, identification of Cryptococcus species still requires strain culture and PCR assays. As described in the literature [7], the positivity rate of India ink detection in the present study was higher in the $\mathrm{Cn}$ group than in the $\mathrm{Cc} / \mathrm{Cl}$ group, similarly for CSF 
detection of cryptococcal antigens which had a much higher positivity rate in the $\mathrm{Cn}$ group. The partial expression of some virulence enzymatic factors in non-neoformans and non-gattii Cryptococcus species as described by K. Ferreira-Paim et al., and mentioned earlier in this manuscript could explain the low reactivity of $\mathrm{Cc} / \mathrm{Cl}$ capsular antigens to the $\mathrm{CrAg}$ assay, which was developed for the detection of $\mathrm{Cn} / \mathrm{Cg}$ species complex antigens. Given the increase in meningitis cases due to non-neoformans and non-gattii species worldwide, it is useful that the reactivity of these species to commercially available $\mathrm{CrAg}$ assays be established in subsequent larger studies [23].

For culture-positive samples with negative $\mathrm{CrAg}$ results, the antigen excess zone (prozone phenomenon) may be the explanation. Dilution of the tested sample could have resolved this discordance.

While $\mathrm{Cn}$ strains were easily identified by MALDI-TOF MS, ITS sequencing, and multiplex PCR serotyping used during the study, only four $\mathrm{Cc} / \mathrm{Cl}$ strains (out of six) were identified by MALDI-TOF MS and all of them had a different profile from the reference agarose gel profile after multiplex PCR. The results of the MALDI-TOF MS identification were only $80 \%$ conclusive for the $C c / C l$ strains. In the remaining cases, it was either an identification with a bad score or an outright wrong identification. As the spectrum generated during sample analysis is compared with the spectra in the manufacturer's database to establish a match, a limited panel of spectra or the absence of spectra of a microbial species in the database could result in a failed species identification. As both species are present in the database used, BD 8326 Bruker, an extraction process using ethanol, formic acid, and acetonitrile might have been necessary to improve the results because of the "big shell" of Cryptococcus spp. The non-neoformans/ non-gattii shell could be more refractory than that of $\mathrm{Cn}$. For its part, the determination of serotypes of $\mathrm{Cc} / \mathrm{Cl}$ strains by classical multiplex PCR targeting LAC1 and CAP64 genes was not possible. Based on its initial application, this PCR was designed to characterize strains of the $\mathrm{Cn} / \mathrm{Cg}$ species complex. Given the superiority of the laccase enzyme activity of the $\mathrm{Cn} / \mathrm{Cg}$ complex over that of non-neoformans and non-gattii species as described above, these results could be partially explained [24].

Although some peritonitis due to non-neoformans and non-gattii Cryptococcus species has been cured by early removal of the catheter without antifungal treatment, others require more intensive treatment because of the fluconazole and 5-flucytosine resistance associated with these isolates [3, 25].

In the present study, $33.3 \%$ of the $\mathrm{Cc} / \mathrm{Cl}$ strains had moderately high MICs to fluconazole $(16-32 \mathrm{mg} / \mathrm{L})$ compared to $8.7 \%$ in the $\mathrm{Cn}$ group. The proportion of $\mathrm{Cc} / \mathrm{Cl}$ strains resistant to 5-flucytosine and fluconazole is evaluated between 50 and $100 \%$ in other studies and higher than in $\mathrm{Cn} / \mathrm{Cg}$ complex, which is more marked than what we could observe $[4,7,20]$. One strain (16.7\%) of the $\mathrm{Cc} / \mathrm{Cl}$ group, $\mathrm{C}$. laurentii, was resistant to amphotericin $B$ which is known as the most effective antifungal agent in the management of Cryptococcus infections by all species $[3,26]$. This same strain was also resistant to 5-flucytosine (16.7\%).

All patients with $\mathrm{Cn}$ meningitis received antifungal agents according to WHO recommendations and guidelines, MSF protocol [27]. In contrast, one patient in the $\mathrm{Cc} / \mathrm{Cl}$ group was treated with fluconazole alone although the strain was susceptible in vitro. Despite this, the patients' therapeutic outcome was not significantly different in the two groups. Patients were selected in MSF-supported clinics where the whole management process is codified. Thus, patients for whom the Cryptococcus identification was provided by the study a few weeks after sample collection were not treated based on this identification. Consequently, 4.3\% of patients in the $\mathrm{Cn}$ group versus $33.3 \%$ of patients in the $\mathrm{Cc} / \mathrm{Cl}$ group were not treated with antifungals. The mean length of hospital stay for patients was 12.4 versus 9.9 days with the usual tri-antifungals, $\mathrm{Cc} / \mathrm{Cl}$, and $\mathrm{Cn}$ groups respectively. Longer hospital stays (60 days) have been described for $C$. albicans meningitis on amphotericin B [28].

\section{Conclusions}

$\mathrm{Cn}$ meningitis is clinically more severe than that caused by the $\mathrm{Cc} / \mathrm{Cl}$ complex due to the high virulence of this species. Accordingly, some biological parameters are more altered in $\mathrm{Cn}$ infection than $\mathrm{Cc} / \mathrm{Cl}$, on one side. The routine biological detection and molecular identification of $\mathrm{Cc} / \mathrm{Cl}$ strains are more delicate than $\mathrm{Cn}$. Plus, $\mathrm{Cc} / \mathrm{Cl}$ strains require high antifungal MICs than $\mathrm{Cn}$ in vitro, on the other side. That is why $\mathrm{Cc} / \mathrm{Cl}$ complex should be considered in HIVIP management with meningitis.

\section{Abbreviations \\ Cc/Cl: Cryptococcus curvatus/C. laurentii; CHME de NGABA: Centre Hospitalier Mère et Enfant de NGABA; CHRB $1^{\text {er }}$ : Centre Hospitalier Roi Baudouin $1^{\text {er }}$; CME LUYINDU: Centre Médical et Evangélique LUYINDU; Cg: Cryptococcus gattii; Cn: Cryptococcus neoformans; CLSI: Clinical Laboratory Standards Institute; CrAg: Cryptococcal Antigen; CSF: Cerebral Spinal Fluid; DNA: DesoxyriboNucleic Acid; EUCAST: European Committee on Antimicrobial Susceptibility Testing; HCCA: Cyano-4-hydroxycinnamic; HIVIP: HIV-Infected Patients; ITS: Internal Transcribed Spacer; LFA: Lateral Flow Antigen; MALDI-TOF MS: Matrix-Assisted Laser Desorption Ionization Time-Of-Flight Mass Spectrometry; MC: Meningea Cryptococcosis; MIC: Minimum Inhibitory Concentration; MSF: Médecins Sans Frontière; rRNA: Ribosomic RiboNucleic Acid; SDA-C: Sabouraud Dextrose Agar-Chloramphenicol.}

Acknowledgements

Not applicable. 


\section{Authors' contributions}

BZ designed the study, wrote, analysed, and interpreted the patient and microbiological data. RS analysed and interpreted the microbiological data. GMU, NL and AB collected data at the hospitals. MM, HS and PK helped to evaluate and edit the manuscript. GMV and MPH acquired funding. All authors read and approved the final manuscript.

\section{Funding}

This research was funded by the Académie de Recherche et d'Enseignement Supérieur (ARES-Belgium) from conception to publication.

\section{Availability of data and materials}

All data analysed and generated in this study are available from the corresponding author on reasonable request.

\section{Declarations}

\section{Ethics approval and consent to participate}

This work was carried out in strict compliance with ethical rules. It has obtained the approval of the Ethics Committee of the Public Health School of the Faculty of Medicine of the University of Kinshasa under the Approval number ESP/CE/071/2019. All patients included in this study were informed of the risks associated with the study and gave their informed consent to participate. Anonymity was guaranteed and the data collected was kept and handled by the research team alone. All methods were carried out in accordance with relevant guidelines and regulations/Declaration of Helsinki.

\section{Consent for publication}

Not applicable.

\section{Competing interests}

The authors declare no competing interests.

\section{Author details}

${ }^{1}$ Molecular Biology Service, Department of Basic Sciences, Faculty of Medicine, University of Kinshasa, Kinshasa, Democratic Republic of Congo. ${ }^{2}$ Department of Infectious Diseases and General Internal Medicine, University Hospital Center of Liege, Liege, Belgium. ${ }^{3}$ Infectious Diseases Service, Department of Internal Medicine/Department of Tropical Medicine, Faculty of Medicine, University of Kinshasa, Kinshasa, Democratic Republic of Congo. ${ }^{4}$ National Reference Center for Mycosis, University Hospital Center of Liege, Liege, Belgium. ${ }^{5}$ Advanced HIV Infection Management Unit, Internal Medicine Department, Centre Hospitalier Mère et Enfant de NGABA, Kinshasa, Democratic Republic of Congo. ${ }^{6}$ Advanced HIV Infection Management Unit, Internal Medicine Department, Centre Médical et Evangélique Révérend LUYINDU, Kinshasa, Democratic Republic of Congo. ${ }^{7}$ Center for Interdisciplinary Research on Medicines, University of Liege, Liege, Belgium.

Received: 22 May 2021 Accepted: 8 November 2021 Published online: 15 November 2021

\section{References}

1. Kwon-Chung KJ, Varma A. Do major species concepts support one, two or more species within Cryptococcus neoformans? FEMS Yeast Res. 2006:6:574-87.

2. Chen SCA, Korman TM, Slavin MA, Marriott D, Byth K, Bak N, et al. Antifungal therapy and management of complications of cryptococcosis due to Cryptococcus gattii. Clin Infect Dis. 2013;57:543-51.

3. Khawcharoenporn T, Apisarnthanarak A, Mundy LM. Non-neoformans cryptococcal infections: a systematic review. Infection. 2007:35:51-8.

4. Johnson LB, Bradley SF, Kauffman CA. Fungaemia due to Cryptococcus laurentii and a review of non-neoformans cryptococcaemia. Mycoses. 1998:41:277-80.

5. Thiru M, Sankh S, Rangaswamy V. Process for biodiesel production from Cryptococcus curvatus. Bioresour Technol. 2011;102:10436-40. https:// doi.org/10.1016/j.biortech.2011.08.102.

6. Nowicka J, Nawrot U, Haus O, Kuliczkowski K, Fonteyne PA, Nolard N. Cryptococcus curvatus in peritoneal fluid of gastric lymphoma patient with complex chromosome aberrations-case report. Mikol Lek. 2007;14:285-7.

7. Mccurdy LH, Billings FT. Infections due to non-neoformans cryptococcal species. Comp Ther. 2003;29:95-101.

8. Jacobs RM, Cochrane SM, Lumsden JH, Norris AM. Relationship of cerebrospinal fluid protein concentration determined by dye-binding and urinary dipstick methodologies. Can Vet J. 1990;31(8):587-8.

9. Library MBTIVD, Library MBTIVD, Ivd MBT, Extension L, Library MBTIVD. Notes de publication. 2019:1-61.

10. Ferrer C, Colom F, Frasés S, Mulet E, Abad JL, Alió JL. Detection and identification of fungal pathogens by PCR and by ITS2 and $5.8 \mathrm{~S}$ ribosomal DNA typing in ocular infections. J Clin Microbiol. 2001;39:2873-9.

11. Ito-Kuwa S, Nakamura K, Aoki S, Vidotto V. Serotype identification of Cryptococcus neoformans by multiplex PCR. Mycoses. 2007;50:277-81.

12. Arendrup MC, Guinea J, Cuenca-Estrella M, Meletiadis J, Moutonn JW, Lagrou K, et al. Method for the determination of broth dilution minimum Inhibitory concentrations of antifungal agents for yeasts. Print Pap Eur. 2015;16:17.

13. Committee TE, Testing AS, Changes N, Pseudomonas E. European Committee on Antimicrobial Susceptibility Testing Breakpoint tables for interpretation of MICs and zone diameters European Committee on Antimicrobial Susceptibility Testing Breakpoint tables for interpretation of MICs and zone diameters. 2015:0-77. http://www.eucast.org/filea

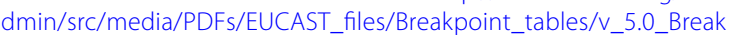
point_Table_01.pdf.

14. Pfaller MA, Messer SA, Boyken L, Rice C, Tendolkar S, Hollis RJ, et al. Global trends in the antifungal susceptibility of Cryptococcus neoformans (1990 to 2004). J Clin Microbiol. 2005;43:2163-7.

15. Temfack E, Boyer-Chammard T, Lawrence D, Delliere S, Loyse A, Lanternier F, et al. New insights into Cryptococcus spp. biology and Cryptococcal meningitis. Curr Neurol Neurosci Rep. 2019;19:81.

16. Kwon-Chung KJ, Fraser JA, Doering TL, Wang Z, Janbon G, Idnurm A, et al. Cryptococcus neoformans and Cryptococcus gattii, the etiologic agents of cryptococcosis. Cold Spring Harb Perspect Med. 2014:4:a019760. https://doi.org/10.1101/cshperspect.a019760.

17. Shankar EM, Kumarasamy N, Bella D, Renuka S, Kownhar H, Suniti S, et al. Pneumonia and pleural effusion due to Cryptococcus laurentii in a clinically proven case of AIDS. Can Respir J. 2006;13:275-8.

18. Banerjee P, Haider M, Trehan V, Mishra B, Thakur A, Dogra V, et al. Cryptococcus laurentii Fungemia. Indian J Med Microbiol. 2013;31:75-7.

19. Calista F, Tomei F, Assalone P, Traficante D, Di Pilla G, Pepe C, et al. Cryptococcus laurentii Diarrhea in a Neoplastic Patient. Case Rep Oncol Med. 2015;2015 Figure 2:1-2.

20. Smith N, Sehring M, Chambers J, Patel P. Perspectives on non-neoformans cryptococcal opportunistic infections. J Community Hosp Intern Med Perspect. 2017;7:214-7. https://doi.org/10.1080/20009666.2017. 1350087.

21. Cano EJ, Yetmar ZA, Razonable RR. Cryptococcus species other than Cryptococcus neoformans and Cryptococcus gattii: are they clinically significant? Open Forum Infect Dis. 2020;7:1-4.

22. Sugita T, Takashima M, Ikeda R, Nakase T, Shinoda T. Intraspecies diversity of Cryptococcus laurentii as revealed by sequences of internal transcribed spacer regions and $28 \mathrm{~S}$ rRNA gene and taxonomic position of C. laurentii clinical isolates. J Clin Microbiol. 2000;38:1468-71.

23. Ferreira-Paim K, Andrade-Silva L, Mora DJ, Lages-Silva E, Pedrosa AL, da Silva PR, et al. Antifungal susceptibility, enzymatic activity, PCRfingerprinting and ITS sequencing of environmental Cryptococcus laurentii isolates from Uberaba, Minas Gerais, Brazil. Mycopathologia. 2012;174:41-52.

24. Ikeda R, Sugita T, Jacobson ES, Shinoda T. Laccase and melanization in clinically important. Society. 2002;40:1214-8.

25. Mocan H, Murphy A, Beattie T, McAllister T. Fungal peritonitis in cidldren on continuous ambulatory peritoneal dialysis. Scot Med J. 1989:34:494-6

26. Bernal-martinez L, Gomez-lopez A, Castelli MV, Mesa-arango ANAC, Zaragoza $\mathrm{O}$, Rodriguez-tudela $\mathrm{J}$, et al. Susceptibility profile of clinical isolates of non-Cryptococcus neoformans/non-Cryptococcus gattii Cryptococcus species and literature review. Med Mycol. 2010;48:90-6.

27. World Health Organization. Guidelines for the diagnosis, prevention and management of cryptococcal disease in HIV-infected adults, 
adolescents and children, march 2018. Genève; 2018. http://www.who. int/fr.

28. Theophilo da Cunha JL. Cryptococcus albidus meningitis. South Med J. 1973;66(11):1230.

\section{Publisher's Note}

Springer Nature remains neutral with regard to jurisdictional claims in published maps and institutional affiliations.
Ready to submit your research? Choose BMC and benefit from:

- fast, convenient online submission

- thorough peer review by experienced researchers in your field

- rapid publication on acceptance

- support for research data, including large and complex data types

- gold Open Access which fosters wider collaboration and increased citations

- maximum visibility for your research: over $100 \mathrm{M}$ website views per year

At BMC, research is always in progress.

Learn more biomedcentral.com/submissions 